there is a variation of 20 to $90 \mathrm{ml}$. in the 24 hours without any treatment and that when the daily output on cough mixtures is compared with the daily output on water there is no significant difference. He undertook a similar experiment to investigate the effects of antispasmodic drugs on sputum production but there is no control period and no conclusions are drawn.

This book contains a great deal of information on chronic bronchitis in adults, but the role of smoking is not discussed and the increased liability of bronchitic patients to post-operative pulmonary complications is not mentioned.

This is an interesting book which is good enough to make one wish that it had been better.

K.N.V.P.

\section{MANAGEMENT OF COELIAC DISEASE}

By Sidney V. HaAs, M.D., and Merrill P. HaAs, M.D. Pp. $x+188$, with 12 illustrations. London and Philadelphia: J. B. Lippincott Co. r95I. 40s.

The first 16 chapters or sections of this difficult book are written in the form of a monograph. A brief histological section is followed by a consideration of the main clinical features, the laboratory findings, theories of causation, accepted forms of treatment and finally the prognosis. Throughout there is extensive reference to the literature; indeed the authors make the claim that the bibliography is 'the most nearly complete that has ever been assembled on the subject.' But if from a monograph the reader expects a critical survey of what is known of the disease and of the relative medical literature, followed perhaps by the presentation of original material illustrating considered theories, then this is hardly a monograph in the accepted sense of the word. The authors have done their utmost to support their ideas, illustrating their theme with a rather sketchy analysis of no less a number than 608 personal cases.

The authors' main claims may be stated very briefly. Firstly, that coeliac disease is merely ' a prolonged intermittent diarrhoeal state resulting in various degrees of malnutrition.' There is no mention of steatorrhoea in this definition, and it is abundantly clear that the authors consider not only that any error there may be in fat digestion or absorption is subsidiary and unimportant, but they constantly insinuate that it is frequently not a feature of the disease. Secondly, they emphatically dislike the concept of fibrocystic disease of the pancreas as a separate entity, and all the work on this condition of recent years is subjected to withering scorn. When they finally discuss the subject they specifically state that, if indeed such a condition occurs, it can be treated, and cured, by precisely the same dietary as straightforward coeliac disease.

The authors' third claim concerns this dietary treatment. They state dogmatically that the only important aspect of the diet in coeliac disease is that it should be free of all 'polysaccharides,' the only carbohydrate permissible being 'fruit sugar.' It follows, therefore, that not only cereal grain and potatoes, but all sweets, even cookies, candies and lollipops are specifically forbidden, whilst milk, since it contains ' the polysaccharide sugar of milk' must first be converted into protein milk before it is suitable. On this diet there is prompt remission of all symptoms and 'eventual complete cure with no relapses, no deaths, no crises, no pulmonary complication and no stunting of growth.'

Finally, in the last chapter entitled 'An Aetiological Hypothesis,' after a modest admission that the aetiology is unknown, the authors put forward a simple explanation. As with crime books, it would be a shame for the reviewer to give away the secret. Needless to say, in the authors' own words, 'this aetiology must be considered completely hypothetical until such time as the ideas in it may be verified by suitable experimental measures.' In this sentence lies the whole keynote of the book. The ideas it puts forward are so simple and are so easy of verification that it is a source of amazement to the reader that coeliac disease has remained for so long a medical puzzle.

\section{MODERN DIETARY TREATMENT}

By Margery Abrahams, M.A., M.Sc., and Elsie M. Widdowson, D.Sc., Ph.D. 3rd Edition. Pp. viii +355 . London: Bailliere, Tindall and Cox. 1951. 21 s.

The authors in the preface to this book, theit third edition, state: 'The shortage of food during' the war made it necessary to consider the nutritional value of every ounce of food imported into the United Kingdom. By using all the available knowledge it became possible to feed the population of the country so well that the general level of health actually improved between 1939 and 1946 . Rationing and subsidies have done so much to make the diets of rich and poor alike.'

Now, we are beginning the year 1952 with the knowledge of financial and economical difficulties ahead, making immense problems for dietitians in both practice and teaching in hospital, and in advising individual out-patients on the management of a special diet at home.

In this third eaition of the book, the general character and scope are largely unaltered. Subjects in the chapters dealing with carbohydrates, proteins, amino acids, minerals and vitamins have been brought up to date.

Chapter IX is devoted to 'Diet in Disturbances of Mineral Metabolism,' special reference being given to low salt diets. A list of foods low in sodium content, together with valuable suggestions for adding flavours without the use of salt, and low salt recipes are appreciated.

The chapter dealing with the dietary rules and regulations laid down by the Mosaic law will be of value to those whose work brings them into contact with people of other creeds.

Valuable tables are included on the chemical composition of food, sources of Vitamin D, the 